\title{
Effects of Nano-CaCO on the Properties of Cement Paste: Hardening Process and Shrinkage at Different Humidity Levels
}

\author{
Yamei Cai, Pengkun Hou, Zonghui Zhou, and Xin Cheng \\ School of Materials Science \& Engineering, University of Jinan, Shandong, China \\ Shandong Provincial Key Laboratory of Preparation and Measurement of Building Materials, Shandong, China
}

\begin{abstract}
The hardening process and volume stability of cement pastes with and without nano- $\mathrm{CaCO}_{3}(\mathrm{NC})$ were studied through investigations on the setting time and shrinkage. Results showed that NC shortened the setting time of cement paste: the initial setting time decreased by 3.9 and $11.1 \%$ when 1 and $3 \%$ NC were added, and the finial setting times were shortened by 6.2 and $15.2 \%$, respectively. The shrinkage of cement paste was compensated by NC, and the effect was more obvious as more NC was added into the cement paste. Although the shrinkage decreased at the lower relative humidity, the degree of hydration of cement can be hindered owing to the lack of sufficient internal curing humidity. Considering the hydration of cement and the volume stability of structure, a high curing humidity was an important factor for improving the durability of NC-modified cement-based materials.
\end{abstract}

\section{INTRODUCTION}

The durability of concrete influences noticeably the service life of the entire structure. So improving the durability of cement-based materials has gained widespread attention (Ghafari, Costa, \& Júlio, 2015; Hou, Cheng, Qian, \& Shah, 2014, 2015; Saloma, Nasution, Imran, \& Abdullah, 2015). Recently, many works suggested that nanotechnology had the potential to make breakthrough in improving the performance of building materials. Reports showed that nanomaterials could accelerate the hydration of cement (GarcíaTaengua, Sonebi, Hossain, Lachemi, \& Khatib, 2015; Hou et al., 2012; Zhang, Cheng, Hou, \& Ye, 2015), increase the mechanical property (Heikal, Ismail, \& Ibrahim, 2015; Nazari \& Riahi, 2011; Nochaiya, Sekine, Choopun, \& Chaipanich, 2015), and the durability (Ghafari et al., 2015; Moradpour, TaheriNassaj, Parhizkar, \& Ghodsian, 2013; Saloma et al., 2015).

Within all the nanomaterials used in cement and concrete, nano- $\mathrm{CaCO}_{3}$ (NC) was one of the extensively researched ones (Camiletti, Soliman, \& Nehdi, 2012; Liu, Chen, Liu, \& Wang, 2012; Qian, Meng, Qian, \& Zhan, 2009; Sato \& Diallo, 2010; Tafraoui, Escadeillas, Lebaili, \& Vidal, 2009). Liu et al. (2012) showed that the initial and final setting times of cement paste can be greatly shortened when 1,2 , and $3 \% \mathrm{NC}$ was added into cement paste. The flexural and compressive strength of cement paste with addition of $\mathrm{NC}$ increased at 7 and 28 days. And the drying shrinkage of cement paste with $1 \% \mathrm{NC}$ was one-third of that of the plain paste. Kawashima, Hou, Corr, and Shah, (2013) reported NC accelerated the rate of hydration of cement, and the effect was more pronounced for the sonicated sample with NC. Sato's result (Sato \& Diallo, 2010) showed that NC shortened the induction period of $\mathrm{C}_{3} \mathrm{~S}$.

Generally, nanomaterials, except for those possessing expansion properties, may increase the shrinkage of cement-based materials owing to their ultrafine particle size. However, it is noted that little work has revealed the effects of NC on the volume stability of cement-based materials (Camiletti et al., 2012; Liu et al., 2012). In this paper, the influences of NC on the hydration of cement were first studied and then the shrinkage characteristics of cement paste with different addition of NC were researched, and the effect of the relative humidity of curing on the shrinkage was also discussed.

\section{MATERIALS AND METHODS}

\subsection{Raw materials}

In this work, P.O 42.5 complying with Chinese standard GB 175-2007 was used and its chemical and physical properties were given in Table 1.

Table 1. Chemical and physical properties of ordinary Portland cement.

\begin{tabular}{cccccccc}
\hline $\mathrm{SiO}_{2}$ & $\mathrm{Al}_{2} \mathrm{O}_{3}$ & $\mathrm{Fe}_{2} \mathrm{O}_{3}$ & $\mathrm{SO}_{3}$ & $\mathrm{CaO}$ & $\mathrm{MgO}$ & $\begin{array}{c}\text { Density } \\
\left(\mathbf{g} / \mathbf{c m}^{3}\right)\end{array}$ & $\begin{array}{c}\text { Fineness } \\
\left(\mathbf{m}^{2} / \mathbf{k g}\right)\end{array}$ \\
\hline 21.1 & 4.7 & 3.5 & 3.3 & 62.9 & 2.8 & 3.1 & 322 \\
\hline
\end{tabular}

Commercially available nano- $\mathrm{CaCO}_{3}$ (NC) with a mean size of $50 \mathrm{~nm}$ was used, and its mineralogical 
feature was shown in Figure 1. XRD result indicated that NC had a good crystallinity.

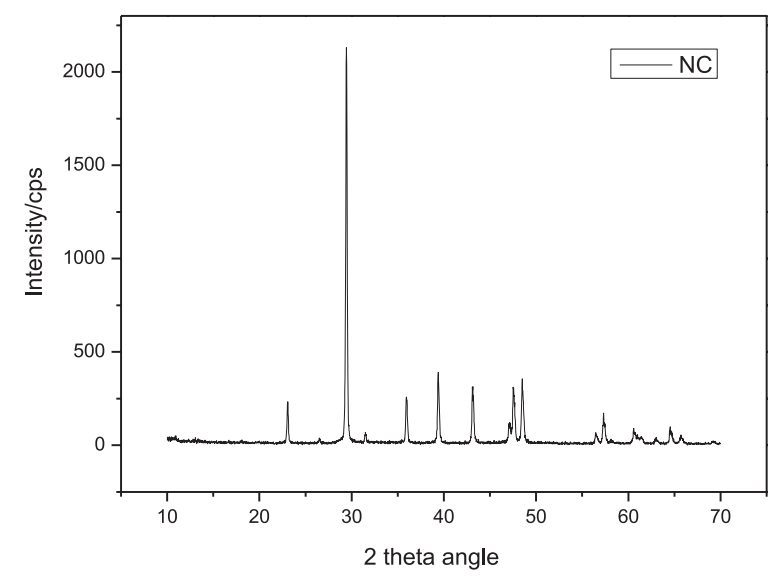

Figure 1. Mineralogy of NC.

\subsection{Methods}

\subsubsection{Sample preparation and curing}

In this paper, cement paste was prepared at water-tobinder ratios of 0.45 . The proportions of raw materials were shown in Table 2. To obtain a well-dispersed suspension, NC was added into water and stirred for $1 \mathrm{~min}$. Then, the suspension was ultrasonically dispersed for another 5 min. The suspension was added into cement, and mixed for another $5 \mathrm{~min}$ before placed in centrifuge tubes.

Table 2. Mix proportions of cement paste/g.

\begin{tabular}{ccccc}
\hline w/b & Mixture type & Cement & Water & NC \\
\hline 0.45 & Control & 500 & 225 & 0 \\
0.45 & $1 \%$ NC & 500 & 227.25 & 5.00 \\
0.45 & $3 \%$ NC & 500 & 231.75 & 15.00 \\
\hline
\end{tabular}

\subsubsection{Setting time}

To assess the influences of NC on the hardening process of cement paste, ASTM C191 (C-191-08, 1995) was followed to determine the initial and final setting times of paste at $w / b$ ratio of 0.45 .

\subsubsection{Shrinkage}

The shrinkage of cement pastes with or without NC was measured at different humidity levels. After sealed curing for 1 day, the paste samples were cut into slices with dimensions of $\phi 27 \mathrm{~mm} \times 5 \mathrm{~mm}$. The initial diameters were recorded before been removed into chambers of 23,43 , and $75 \% \mathrm{RH}$ at room temperature. Then, the diameters of the samples were recorded at different ages. The average of three samples was taken as the representative value.

\section{RESULTS AND DISCUSSION}

\subsection{Setting time}

The influences of NC on the hardening process of cement pastes at $\mathrm{w} / \mathrm{b}$ ratio of 0.45 were presented in Table 3. It showed in Table 3 that the initial setting times were shortened by 3.9 and $11.1 \%$ when 1 and $3 \%$ NC was added, and the finial setting time decreased by 6.2 and $15.2 \%$, respectively. A comparable result was found in reports (Camiletti et al., 2012; Kawashima et al., 2013; Liu et al., 2012): NC shortened the setting times of cement-based materials significantly. This could be due to the seeding effect of NC in the cement-based materials: NC acted as seeds for the acceleration of the hydration of cement (Sato \& Diallo, 2010).

Table 3. Effect of NC on the hardening of cement pastes $(\mathrm{w} / \mathrm{b}=0.45)$.

\begin{tabular}{ccc}
\hline $\mathbf{w} / \mathbf{b}=\mathbf{0 . 4 5}$ & Initial setting & Final setting \\
\hline Control & $647(100 \%)$ & $693(100 \%)$ \\
$1 \% \mathrm{NC}$ & $622(96 \%)$ & $650(94 \%)$ \\
$3 \% \mathrm{NC}$ & $575(89 \%)$ & $588(85 \%)$ \\
\hline
\end{tabular}

\subsection{Shrinkage at different humidity levels}

To assess the effects of NC on the volume stability of cement paste, the shrinkage of cement paste with different addition of NC at different humidity levels was studied, and the results were shown in Figure 2.

It can be seen in Figure 2 that NC compensated the shrinkage of cement paste to some extent. The shrinkage-compensating capabilities were more significant when $3 \% \mathrm{NC}$ was added into paste in comparison to $1 \% \mathrm{NC}$. The reasons for the decrease of the shrinkage of cement paste with $\mathrm{NC}$ could be that the pores of cement paste were refined by addition of NC, which can be used as an internal restraint against shrinkage. So the volume decrease of cement paste with NC was lesser than the plain samples. The comparable results of shrinkage compensating of cement paste containing NC also can be seen in the report by Liu et al. (2012).

The relative humidity effected noticeably the volume variation of cement paste, as shown in Figure 2. The value of shrinkage increased at first and then decreased with the increase of relative humidity.

Generally speaking, when the curing humidity is low $(2-42 \%)$, the changes in the surface tension of solid gel particles are the predominant mechanism of shrinkage (Gao, Ma, \& Ba, 2005). The stress $P$ can be characterized by:

$$
\mathrm{P}=\frac{2 \gamma}{r}
$$




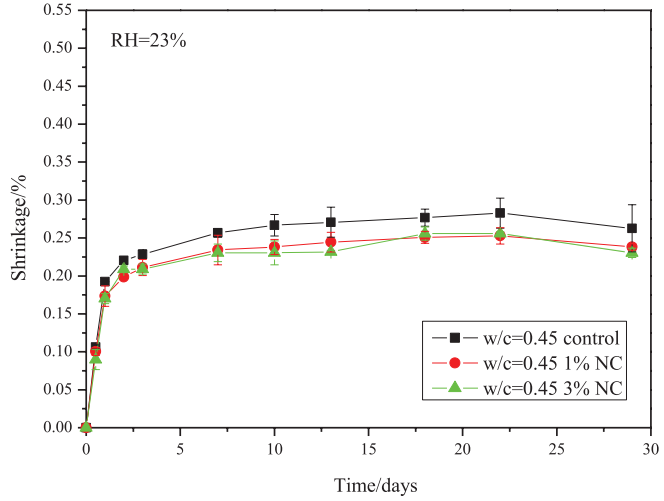

(a)

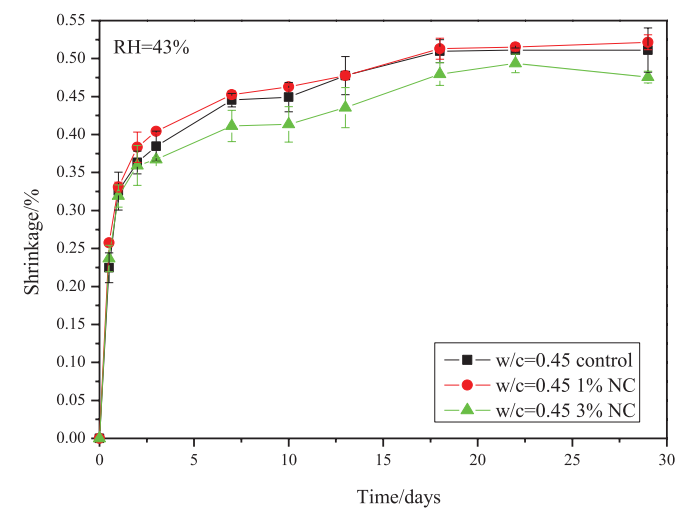

(b)

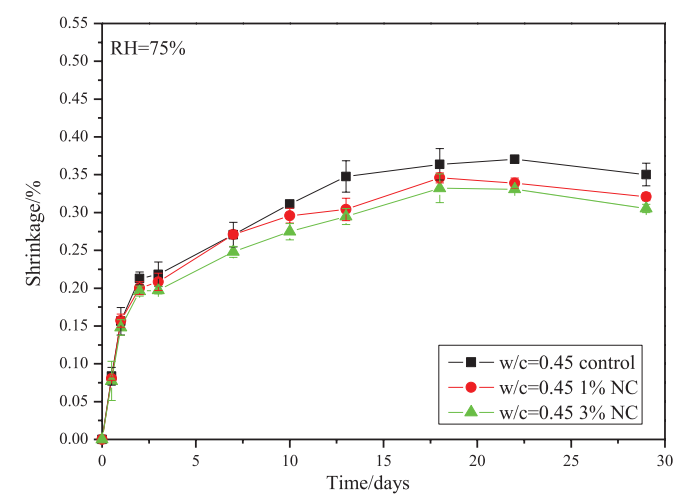

(c)

Figure 2. Effects of NC on the shrinkage of cement paste at different humidity levels.

where $\gamma$ stands for surface tension, $r$ stands for the radius of gel particles (Van Breugel, 2001). When the curing humidity is bigger than $42 \%$, the capillary stress is a key factor. And the process can be characterized by the Kelvin formula (Ma, Wen, Wang, Yan, \& XiaoJian, 2007):

$$
\ln \frac{P_{r}}{P_{0}}=\ln H=\frac{1}{R T} \cdot \frac{M}{\rho} \cdot \frac{2 \sigma}{r}
$$

where $P_{0}$ and $P_{r}$ denote saturated vapor pressure of plane water and curve surface water, respectively, $H$ denotes the relative humidity, $R$ denotes the gas constant, $T$ denotes temperature, $M$ denotes the mole mass of water, $\rho$ denotes the density of water, $\sigma$ denotes the surface tension of water, and $r$ denotes the curvature radius of water in the pore.

When the relative humidity increased from 23 to $43 \%$, the vapour pressure of the adsorbed water on the solid gel particles increased, so the solid surface tension increased, and the change of the radius of gel particles was small. According to formula (1), the shrinkage increased. With the increasing of humidity from 43 to $75 \%$, from formula (2), the water placed in the larger pore began to evaporate, and when a smaller capillary tension was produced, so the shrinkage decreased. In addition, when the curing humidity was low, for example, $23 \% \mathrm{RH}$, the hydration of cement can be hindered owing to the lack of sufficient internal curing humidity. It can be seen in Figure 2(a) that a small shrinkage trend was observed after 7 days, but the trend of equilibrium was postponed to 18 days in Figures 2(b) and (c).

Considering the hydration of cement and the volume stability of structure, a high curing humidity of samples was an important factor for improving the durability of cement-based materials.

\section{CONCLUSION}

(1) Nano- $\mathrm{CaCO}_{3}$ (NC) shortened the setting time of cement paste and accelerated the hardening process of cement;

(2) NC decreased the shrinkage of cement paste, and the effect was more pronounced when the addition of NC was high;

(3) Considering the hydration of cement and the volume stability of structure, high curing humidity of samples was an important factor for improving the durability of cement-based materials.

\section{ACKNOWLEDGMENT}

Support from National High Technology Research and Development Program ("863 Program," 2015AA034701) is greatly acknowledged.

\section{REFERENCES}

C-191-08, A. (1995). Standard test methods for time of setting of hydraulic cement by Vicat needle.

Camiletti, J., Soliman, A. M., \& Nehdi, M. L. (2012). Effects of nano- and micro-limestone addition on early-age properties of ultra-high-performance concrete. Materials and Structures, 46(6), 881-898.

Gao, X., Ma, B., \& Ba, H. (2005). Influence of temperature and humidity on drying shrinkage of cement-based materials. Concrete, 194(12), 35-38. 
García-Taengua, E., Sonebi, M., Hossain, K. M. A., Lachemi, M., \& Khatib, J. (2015). Effects of the addition of nanosilica on the rheology, hydration and development of the compressive strength of cement mortars. Composites Part B: Engineering, $81,120-129$.

Ghafari, E., Costa, H., \& Júlio, E. (2015). Critical review on eco-efficient ultra high performance concrete enhanced with nano-materials. Construction and Building Materials, 101, 201-208.

Heikal, M., Ismail, M. N., \& Ibrahim, N. S. (2015). Physico-mechanical, microstructure characteristics and fire resistance of cement pastes containing $\mathrm{Al}_{2} \mathrm{O}_{3}$ nano-particles. Construction and Building Materials, 91, 232-242.

Hou, P., Cheng, X., Qian, J., \& Shah, S. P. (2014). Effects and mechanisms of surface treatment of hardened cement-based materials with colloidal nanoSiO ${ }_{2}$ and its precursor. Construction and Building Materials, 53, 66-73.

Hou, P., Cheng, X., Qian, J., \& Shah, S. P. (2015). Characteristics of surface-treatment of nano- $\mathrm{SiO}_{2}$ on the transport properties of hardened cement pastes with different water-to-cement ratios. Cement and Concrete Composites, 55, 26-33.

Hou, P., Chenga, X., Qianc, J., Zhanga, R., Caoa, W., \& Shahd, S. P. (2012). Effects of colloidal nanoSiO ${ }_{2}$ on fly ash hydration. Cement and Concrete Composites, 34(10), 1095-1103.

Kawashima, S., Hou, P., Corr, D. J., \& Shah, S. P. (2013). Modification of cement-based materials with nanoparticles. Cement and Concrete Composites, 36, 8-15.

Liu, X., Chen, L., Liu, A., \& Wang, X. (2012). Effect of Nano- $\mathrm{CaCO}_{3}$ on properties of cement paste. Energy Procedia, 16, 991-996.

Ma, B.-G., Wen, X.-D., Wang, M.-Y., Yan, J.-J., \& Xiao-Jian, G. (2007). Drying shrinkage of cementbased materials under conditions of constant temperature and varying humidity. Journal of China University of Mining and Technology, 17(3), 428-431.
Moradpour, R., Taheri-Nassaj, E., Parhizkar, T., \& Ghodsian, M. (2013). The effects of nanoscale expansive agents on the mechanical properties of non-shrink cement-based composites: The influence of nano-MgO addition. Composites Part B: Engineering, 55, 193-202.

Nazari, A., \& Riahi, S. (2011). The effects of $\mathrm{TiO}_{2}$ nanoparticles on physical, thermal and mechanical properties of concrete using ground granulated blast furnace slag as binder. Materials Science and Engineering: A, 528(4-5), 2085-2092.

Nochaiya, T., Sekine, Y., Choopun, S., \& Chaipanich, A. (2015). Microstructure, characterizations, functionality and compressive strength of cementbased materials using zinc oxide nanoparticles as an additive. Journal of Alloys and Compounds, $630,1-10$.

Qian, K. L., Meng, T., Qian, X. Q., \& Zhan, S. L. (2009). Research on some properties of fly ash concrete with nano- $\mathrm{CaCO}_{3}$ middle slurry. Key Engineering Materials, 406-405, 186-190.

Saloma, Nasution, A., Imran, I., \& Abdullah, M. (2015). Improvement of concrete durability by nanomaterials. Procedia Engineering, 125, 608-612.

Sato, T., \& Diallo, F. (2010). Seeding effect of nano$\mathrm{CaCO}_{3}$ on the hydration of tricalcium silicate. Transportation Research Record: Journal of the Transportation Research Board, 2141, 61-67.

Tafraoui, A., Escadeillas, G., Lebaili, S., \& Vidal, T. (2009). Metakaolin in the formulation of UHPC. Construction and Building Materials, 23(2), 669-674.

Van Breugel, K. (2001). Numerical modelling of volume changes at early ages-potential, pitfalls and challenges. Materials and Structures, 34(5), 293-301.

Zhang, R., Cheng, X., Hou, P., \& Ye, Z. (2015). Influences of nano- $\mathrm{TiO}_{2}$ on the properties of cement-based materials: Hydration and drying shrinkage. Construction and Building Materials, 81, 35-41. 